\title{
Evaluation of $\left(\left(\mathrm{La}_{0.60} \mathrm{Sr}_{0.40}\right)_{0.95} \mathrm{Co}_{0.20} \mathrm{Fe}_{0.80} \mathrm{O}_{3-\mathrm{x}}\right)$ - $\mathrm{Ag}$ composite anode for direct ammonia solid oxide fuel cells and effect of $P d$ impregnation on the electrochemical performance
}

\author{
Shambhu Singh Rathore ${ }^{a}$, Aniruddha P. Kulkarnia*, Daniel Fini ${ }^{a}$, Sarbjit Giddey ${ }^{a}$, Aaron \\ Seeber ${ }^{\mathrm{b}}$ \\ a: CSIRO Energy, Private Bag 10, Clayton South 3169, Victoria, Australia| \\ b: CSIRO Manufacturing, Private Bag 31, Clayton South 3169, Victoria, Australia \\ *Corresponding author email: Aniruddha.Kulkarni@csiro.au
}

\begin{abstract}
Ammonia produced using renewable hydrogen is being viewed as a promising media for the export of energy from locations rich in renewable energy sources. Solid oxide fuel cells (SOFCs) are efficient devices for converting such exported ammonia back into electricity at the point of use, however investigations on materials and operating regime for direct ammonia fuelled SOFCs are limited. The studies on fuel electrodes tailored specifically for ammonia fuel are limited. In this work, we evaluated the direct ammonia SOFC performance with SilverLanthanum Strontium Cobalt Ferrite (Ag-LSCF) composite anode and a novel Palladium (Pd) nanoparticle decorated Silver-Lanthanum Strontium Cobalt Ferrite (Pd-Ag-LSCF) composite anode in the temperature range of $500{ }^{\circ} \mathrm{C}$ to $800{ }^{\circ} \mathrm{C}$. It is hypothesised that Palladium nanoparticles in the anode provide the hydrogen dissolution and shift the ammonia decomposition reaction towards the right. The cell performance was evaluated with both hydrogen and ammonia as fuels and a clear-cut improvement in the performance was observed with the addition of Pd for both the fuels. The results showed a performance enhancement by $20 \%$ and $43 \%$ with hydrogen and ammonia fuels respectively from the Pd addition of Ag-LSCF anode. Open circuit voltage (OCV) values of the cells with hydrogen and ammonia fuel recorded over the temperature range of $500{ }^{\circ} \mathrm{C}$ to $800{ }^{\circ} \mathrm{C}$ indicated the possibility of direct electro-oxidation of ammonia in SOFCs.
\end{abstract}

Keywords: Anode, Ammonia, SOFC, Energy conversion, Energy storage, Renewable energy

\section{Introduction}

A substantial decrease in the levelised cost of renewable electricity production has been observed over the past decade due to advances in engineering, and increased market penetration of solar and wind power electricity generators. Despite these advances, the actual penetration of non-hydro related renewables remains limited due to the uneven distribution of renewables and their inherent intermittency. In response to these challenges, the avenues for long term energy storage and transport in the form of different chemicals and fuels are being explored. While batteries cater for short term energy storage requirements, for longer terms, energy storage in the form of storable and transportable chemicals is sought. Hydrogen is a lead contender among these chemical storage techniques; however, the storage and transport of hydrogen is still expensive $[1,2]$. In the search for alternatives, ammonia has emerged as a promising candidate for long term storage and transport of renewable energy due to its high gravimetric energy density of $5.2 \mathrm{kWh} / \mathrm{kg}$ and high hydrogen content of $121 \mathrm{~g} / \mathrm{L}$ [3]. Ammonia can be easily compressed and stored in liquid form under relatively mild conditions $(100 \mathrm{kPa}$ 
pressure or $-33^{\circ} \mathrm{C}$ temperature) and there is extensive infrastructure already present for transport and handling, as around $200 \mathrm{M}$ tonnes of ammonia per annum is already produced globally [3]. One of the major hurdles in the application of ammonia as an energy carrier is the limited number of pathways for the utilisation of transported ammonia for power generation. The current approaches involve energy-intensive multi-step processes for the cracking of ammonia and subsequent hydrogen separation and compression before it can be used in fuel cell vehicles or for electricity generation. Ammonia-fed solid-oxide fuel cells (SOFCs) offer a highly efficient pathway for ammonia-into-electricity conversion in a single step without the need for external ammonia cracking. This technology offers the highest round-trip electric and thermal efficiencies ( $>50 \%)$ amongst all known technologies for ammonia utilisation [3]. There have been concerns about the possibility of $\mathrm{NO}_{\mathrm{x}}$ formation in ammonia fuelled SOFCs with oxygen ion conductor electrolyte. However, several recent experimental studies have reported that no $\mathrm{NO}_{\mathrm{x}}$ formation was observed at the operating temperatures less than $900{ }^{\circ} \mathrm{C}$, and only about $5 \mathrm{ppm}$ at $1000^{\circ} \mathrm{C}$ [4-6]. Despite efficiency advantages, direct ammonia fed solid oxide fuel cells (DA-SOFC) have not been studied extensively and materials specifically tailored for efficient ammonia utilisation have not yet been developed. Most of the experimental investigations of DA-SOFCs are focussed around nickel-based anodes [7-9]. Nickel metal is a well-established catalyst that promotes ammonia cracking; however Ni-based anodes still face challenges in commercialisation such as redox stability, the endothermic nature of ammonia decomposition and the possibility of forming nickel nitrides in the presence of ammonia at lower operating temperatures $[9,10]$. In that context, further research is sought to evaluate alternate electrodes and to better understand the reaction mechanism. Here we report a novel composite anode decorated with a hydrogen-absorbing metal for use in an ammonia SOFC. The perovskite phase is A-site deficient Lanthanum Strontium Cobalt Ferrite $\left(\mathrm{La}_{0.60} \mathrm{Sr}_{0.40}\right)_{0.95} \mathrm{Co}_{0.20} \mathrm{Fe}_{0.80} \mathrm{O}_{3-\mathrm{x}}$ which is typically used as a cathode (air electrode) in $\mathrm{SOFC}$; however, more recently this perovskite has been evaluated as a fuel electrode for fuel cells and also in solid oxide electrolysers [11] [12]. Despite potential phase changes and being a p-type semiconductor, SOFCs with LSCF anodes have delivered promising performance when a conducting phase such as silver is mixed with LSCF or introduced as a current collection layer [13-15]. In this work, we report a response of planar SOFC with Ag-LSCF composite anode for ammonia fuel. We, for the first time also report initial investigations on the effect of addition of palladium which could enhance ammonia dissociation by allowing faster dissolution of hydrogen, which can then be transported to triple phase boundary either via bulk or surface diffusion of hydrogen.

\section{Experimental}

\subsection{Materials and cell fabrication}

Two anodes were prepared for testing in this work with identical electrolyte and cathode in an SOFC planar cell arrangement. One anode comprised $\left(\mathrm{La}_{0.60} \mathrm{Sr}_{0.40}\right)_{0.95} \mathrm{Co}_{0.20} \mathrm{Fe}_{0.80} \mathrm{O}_{3-\mathrm{x}-\delta}$ (LSCF) (Fuel Cell Materials Inc, OH, USA) and Silver powder (Alfa Aesar) mixed in a 65:35 ratio by weight with commercial ink vehicle (Fuel Cell Materials). The second anode was as the first, an LSCF-Ag composite anode however, with additional palladium catalyst particles. The anode with Pd catalyst is referred to as "Pd-Ag-LSCF" and the one without Pd as "Ag-LSCF". The Pd-Ag-LSCF electrode was synthesised by ultrasonically dispersing LSCF powder into an aqueous solution of Pd nitrate dihydrate (Sigma Aldrich). A target weight of Pd catalyst was 2 $\mathrm{wt} \%$ of the anode. After dispersing, the solution was air dried followed by calcination at 950 ${ }^{\circ} \mathrm{C}$ for $2 \mathrm{hrs}$. After which the aforementioned powder was mixed with Silver powder in a 65:35 ratio by weight with ink vehicle. Electrolyte-supported half-cells (Fiaxell SOFC Technologies, 
Switzerland) consisting of an LSCF cathode layer with Gadolinium doped Ceria (GDC) interlayer on a $3 \mathrm{~mol} \%$ Yttria-stabilised Zirconia (3-YSZ) electrolyte support were brush coated with in-house prepared anode slurries as described above to obtain an active anode area of $10.17 \mathrm{~cm}^{2}$ (Figure 1). Prepared cells were subsequently dried and sintered at $820{ }^{\circ} \mathrm{C}$ for 2 hours in air. Such a low sintering temperature for composite anode was selected based upon the previously reported studies for such composite electrodes $[\underline{11}, \underline{12}, \underline{16}, \underline{17}]$. More work might be required to further optimise the sintering temperature to obtain suitable microstructure and adhesion.

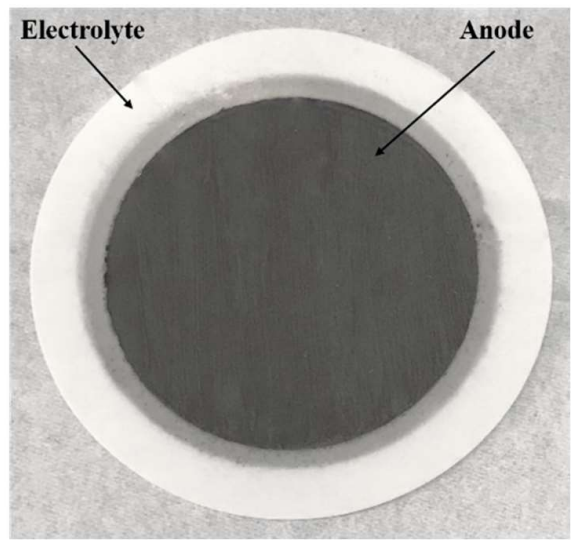

Figure 1. Electrolyte-supported cell and coated anode with an active area of $10.17 \mathrm{~cm}^{2}$.

Silver paste was coated on the anode side of sintered cells for optimal current collection. Silver coated electrolyte-supported cells (ESC) were sintered for 1 hour at $800{ }^{\circ} \mathrm{C}$ in air. The above prepared cells were assembled in a Fiaxell assembly as shown in Figure 2. Nickel mesh was used in the cell fixture for current collection on the anode side while a gold mesh was used on the cathode side. Mica sheet was used as sealant to provide hermetic sealing between the fuel and the air chambers of the cell fixture. Current collector meshes were spring-loaded to provide firm contact between the current collector mesh and cell and to ensure sealing.

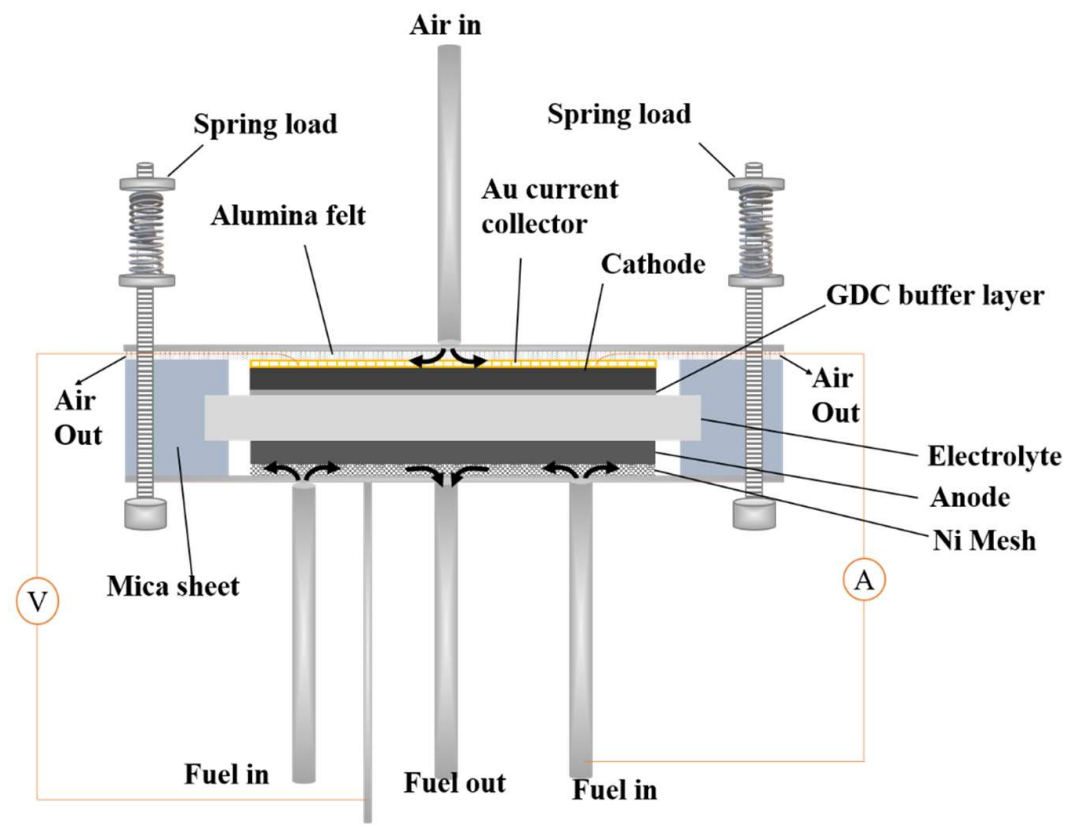

Figure 2. Schematic diagram of Fiaxell fuel-cell setup and assembly. 


\subsection{Material Characterisation}

A phase assemblage of Ag-LSCF and Pd-Ag-LSCF anode materials were analysed using Xray Diffraction (XRD) before and after cell operation. A Rigaku SmartLab, equipped with a rotating anode $\mathrm{CuK} \alpha$ source $(45 \mathrm{kV}, 200 \mathrm{~mA})$, and Hypix 3000 detector, was employed to obtain the $\mathrm{x}$-ray diffractograms. The diffractometer was operated in Bragg-Brentano mode with a $12^{\circ}$ incidence slit, $20 \mathrm{~mm}$ receiving slit and a beam limiting mask of $10 \mathrm{~mm}$. Data was collected over the $2 \theta$ range $5^{\circ}$ to $130^{\circ}$ with a step size of $0.01^{\circ}$ and a scan rate of 2 degrees per minute.

Analyses were performed on the collected XRD data using the Bruker XRD search match program EVA ${ }^{\mathrm{TM}} 5$. Crystalline phases were identified using the ICDD-JCPDS powder diffraction database. Rietveld analysis was performed on the data using the Bruker TOPAS ${ }^{\mathrm{TM}}$ V5 program to determine wt $\%$ values. Background signal was described using a combination of a Chebyshev polynomial linear interpolation function and $1 / x$ function. Cell parameters, vertical sample displacement, peak full width at half maximum, scale factor and preferred orientation were all refined. For wt $\%$ values, error ranges were calculated based on three estimated standard deviations as calculated by TOPAS.

Microstructure images and EDS mappings were obtained Field Emission Scanning Electron Microscopy (FESEM; Merlin-Zeiss Ultra-Plus with a Gemini II column, Germany).

\subsection{Cell performance evaluation}

Cell performance tests were conducted at temperatures starting from $500{ }^{\circ} \mathrm{C}$ and at intervals of $100{ }^{\circ} \mathrm{C}$ thereafter to a maximum temperature of $800{ }^{\circ} \mathrm{C}$, with both pure hydrogen (BOC, Australia) and pure ammonia (Coregas, Australia) as fuels. Hydrogen and ammonia flow rates of $75 \mathrm{ml} / \mathrm{min}$ and $50 \mathrm{ml} / \mathrm{min}$ were used on the anode side respectively. For both hydrogen and ammonia testing an air flow rate of $75 \mathrm{ml} / \mathrm{min}$ was used on the cathode side. The current voltage (I-V) characterisation and electrochemical impedance spectroscopy (EIS) analyses at opencircuit voltage (OCV) were performed with hydrogen and ammonia fuel sequentially on the anode side at the interval of every $100 \mathrm{C}^{\circ}$ from $500^{\circ} \mathrm{C}$ to $800^{\circ} \mathrm{C}$. Cell performance evaluation was performed using a Versastat4 (Princeton Applied Research, USA). For EIS, amplitude of $20 \mathrm{mV}$ was used. EIS was recorded at open circuit voltage (OCV). After performance evaluation at different temperatures, a short-term stability test for $60 \mathrm{hrs}$ were conducted for both cells with ammonia fuel.

\section{Result and Discussion}

\subsection{Materials characterization}

Figure 3 shows an SEM image of the surface of as-prepared Pd infiltrated Ag-LSCF anode on the cell along with EDS mapping shown in Figure 4. The image and EDS map show uniformly distributed spherical Pd particles with considerable variation in particle size from about $25 \mathrm{~nm}$ to $100 \mathrm{~nm}$. Figure 5 shows an X-ray diffractogram of the as-prepared Pd infiltrated Ag-LSCF anode, which is dominated by peaks from the YSZ substrate, Ag and LSCF. No Pd peaks were observed possibly because of uniform dispersion of $\mathrm{Pd}$ particles and resolution limitation of lab XRD. SEM images of as prepared and after test Ag-LSCF (Figure S1) are provided in supplementary information which is consistent with the previously reported results [16]. 


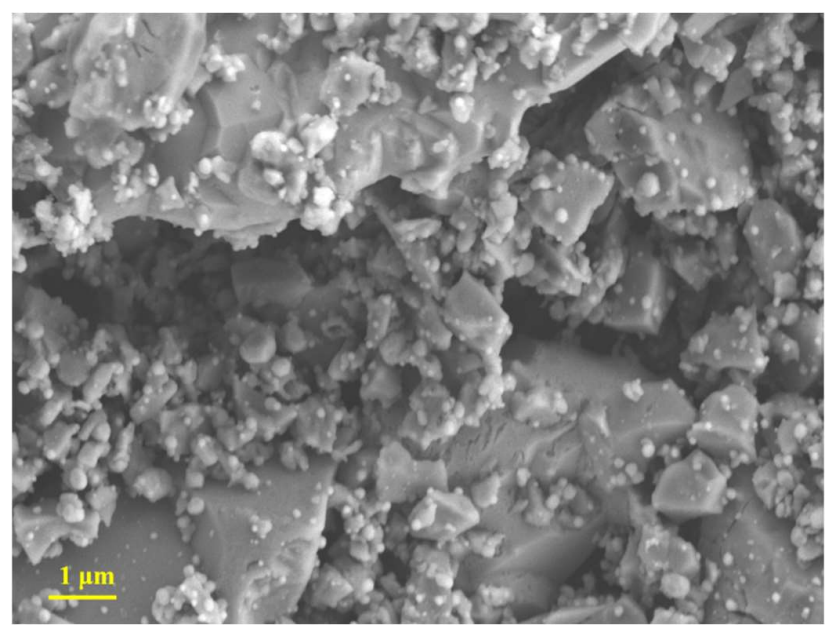

Figure 3. SEM image of Pd infiltrated Ag-LSCF anode surface before testing.

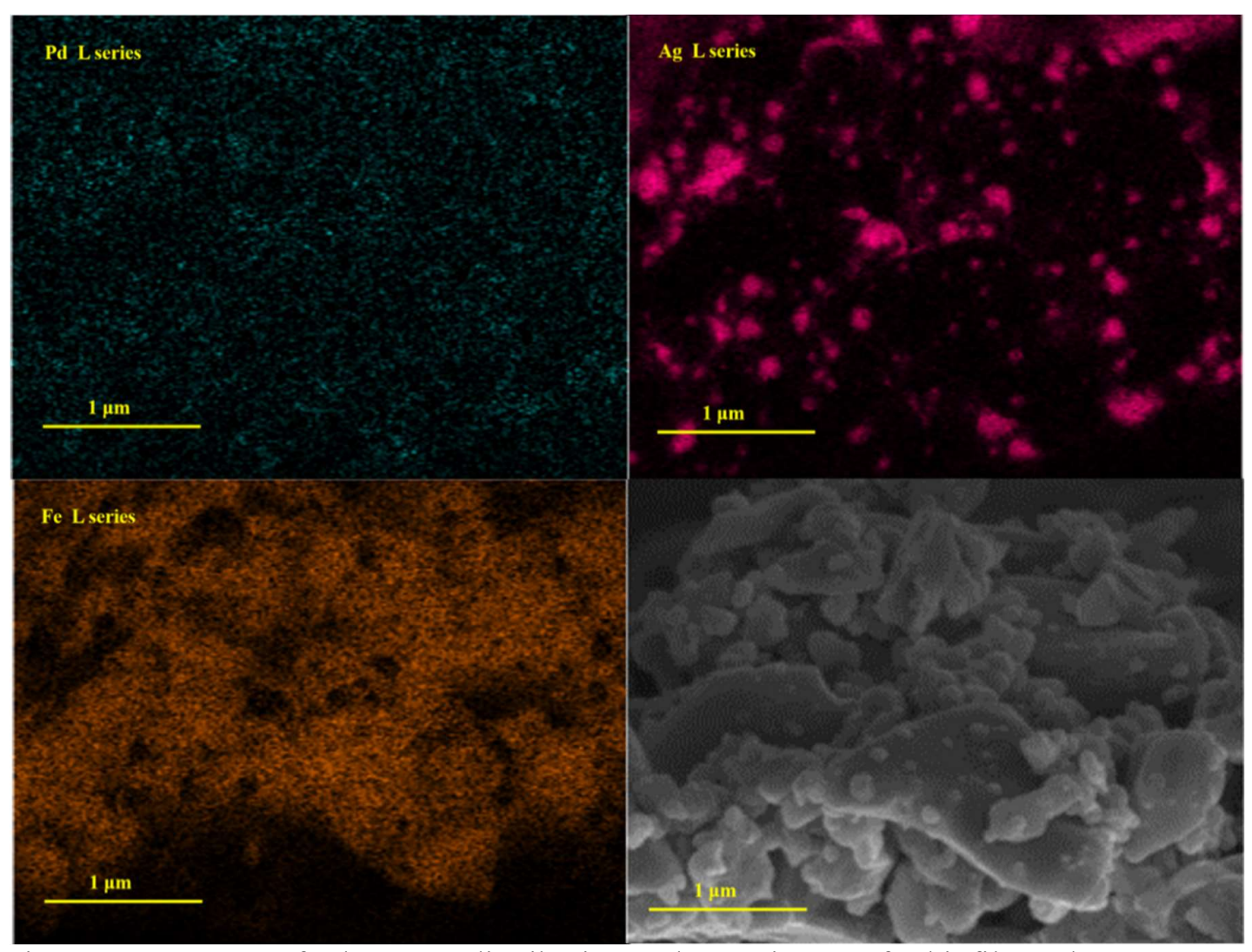

Figure 4. EDS map of Pd, Ag, Fe distribution and SEM image of Pd infiltrated Ag-LSCF anode surface before testing. 


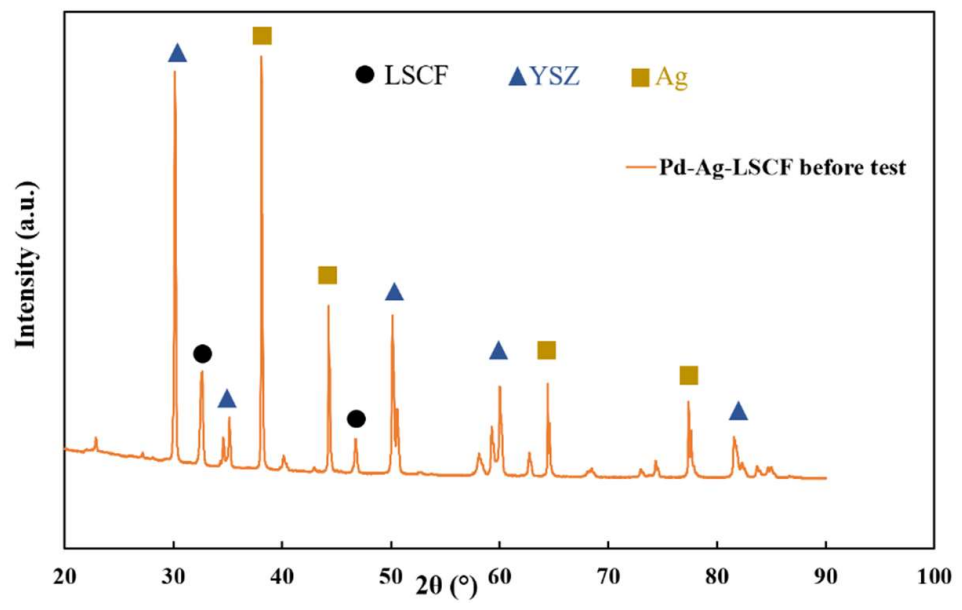

Figure 5. X-ray diffractograms collected from the Pd infiltrated Ag-LSCF anode surface before testing.

\subsection{Temperature effects on OCV and performance}

Figure 6 shows the OCV of SOFC with Pd-Ag-LSCF anode with hydrogen and ammonia fuels as a function of temperature. The OCV decreased linearly with the temperature for hydrogen fuel whereas it showed an overall increase in OCV for ammonia fuel, except for a slight drop when the temperature was increased from $600{ }^{\circ} \mathrm{C}$ to $700^{\circ} \mathrm{C}$. Ammonia can react in SOFCs either by producing hydrogen as a result of in-situ cracking in the anode chamber or near the electrode surface (Reaction R-1) or in principle, by direct electrochemical oxidation (Reaction $\mathrm{R}-2$ ). A mixed reaction mechanism with a contribution from both Reaction R1 and R2 is also possible [18].

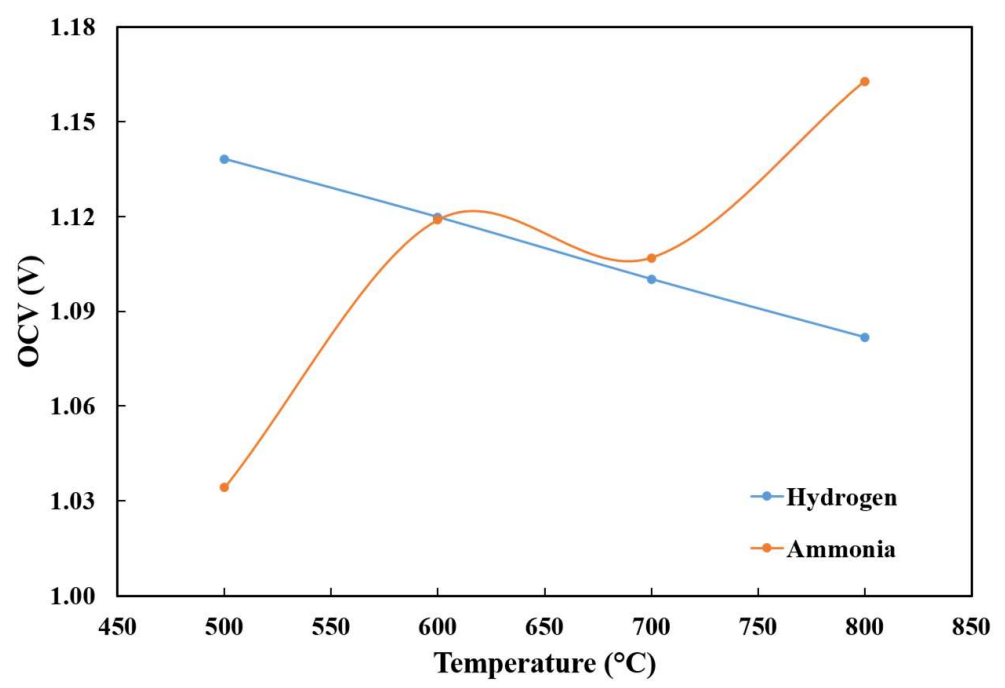

Figure 6. Experimental OCV of Ag-LSCF//YSZ//GDC/LSCF cell with dry hydrogen and ammonia fuels as a function of temperature.

$$
\begin{array}{cc}
2 \mathrm{NH}_{3} \rightarrow \mathrm{N}_{2}+3 \mathrm{H}_{2} & \mathrm{R}-1 \\
2 \mathrm{NH}_{3}+5 \mathrm{O}^{2-} \rightarrow 2 \mathrm{NO}+3 \mathrm{H}_{2} \mathrm{O}+10 \mathrm{e}^{-} & \mathrm{R}-2
\end{array}
$$


The experimentally observed trends in OCV follow the trend in cell EMF (electromotive force) values (Table 1) for the hydrogen electro-oxidation and more interestingly for direct electrochemical oxidation of ammonia [18]. This trend does hint at the possibility of direct electrochemical oxidation or prominence of direct electro-oxidation of ammonia to generate electrical energy along with the hydrogen cracking reaction. Similar observations have been reported by Akimoto et al. [18]. Although OCV of cell is related to reaction mechanism, it is acknowledged that further studies are required to elucidate reaction mechanism considering sensitivity of OCV to experimental conditions and sealing. It is plausible that power generation in ammonia SOFCs at lower temperatures proceeds via mixed reaction mechanism with a combination of direct electrochemical oxidation and oxidation of hydrogen generated by ammonia dissociation. This is particularly interesting, noting that the efficiency for direct electrochemical oxidation of ammonia (R2) is almost $20 \%$ higher than the oxidation of hydrogen produced in-situ by cracking (R1).

Table 1: Cell EMF for hydrogen and ammonia fuel

\begin{tabular}{ccccc}
\hline \multirow{2}{*}{ Temperature $\left({ }^{\circ} \mathbf{C}\right)$} & \multicolumn{2}{c}{ Hydrogen fuel } & \multicolumn{2}{c}{ Ammonia fuel } \\
\cline { 2 - 5 } & $\Delta \mathbf{G}(\mathbf{K J} / \mathbf{m o l})$ & $\mathbf{E}^{\circ}(\mathbf{V})$ & $\Delta \mathbf{G}(\mathbf{K J} / \mathbf{m o l})$ & $\mathbf{E}^{\circ}(\mathbf{V})$ \\
\hline 500 & -204.93 & 1.06 & -342.94 & 1.18 \\
600 & -199.54 & 1.03 & -346.14 & 1.20 \\
700 & -194.06 & 1.00 & -349.86 & 1.21 \\
800 & -188.52 & 0.98 & -353.26 & 1.22 \\
\hline
\end{tabular}

\subsection{Electrode performances with hydrogen fuel}

Figure 7 compares the current density-voltage-power density (I-V-P) curves for both Ag-LSCF and Pd-Ag-LSCF anodes with dry hydrogen fuel. It is observed that the maximum power density was improved by almost $20 \%$, to $73 \mathrm{~mW} / \mathrm{cm}^{2}$ from $59 \mathrm{~mW} / \mathrm{cm}^{2}$ with $\mathrm{Pd}$ infiltration. The comparison of EIS spectra (Figure 8) reveals differences in both ohmic as well as polarisation resistances of the cell with both being higher for the Ag-LSCF cell without Pd infiltration. For both electrodes, the EIS seems to be consisting of at least two distinguishable arcs labelled as high frequency (HF) and low frequency (LF). These two arcs encompass the polarization resistance from both anode and cathode.

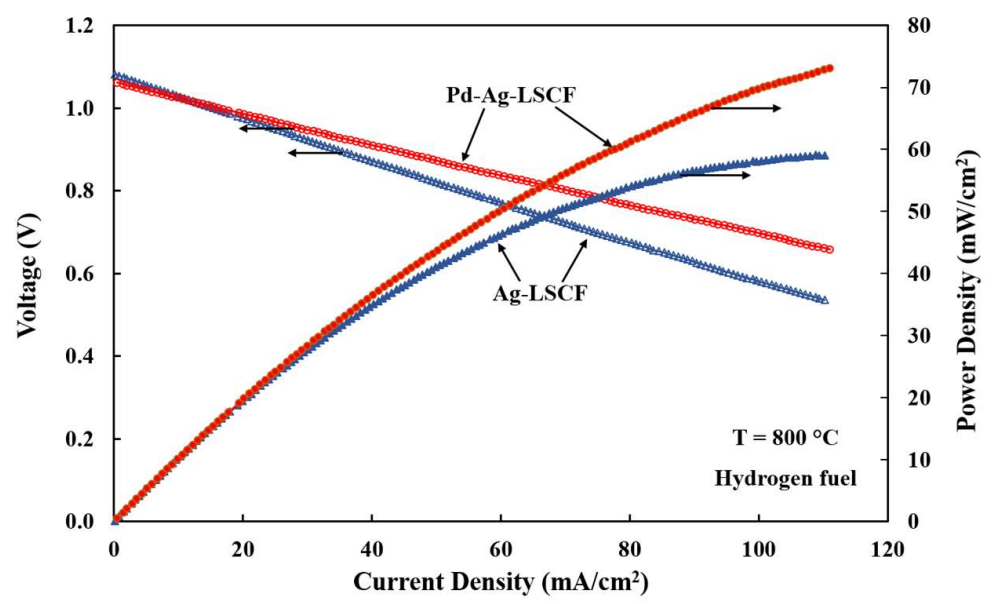

Figure 7. Voltage-current-power density characteristics with hydrogen as a fuel for Ag$\mathrm{LSCF} / / \mathrm{YSZ} / / \mathrm{GDC} / \mathrm{LSCF}$ cell and Pd-Ag-LSCF//YSZ//GDC/LSCF cell (hydrogen $=75$ $\mathrm{ml} / \mathrm{min}$, air $=75 \mathrm{ml} / \mathrm{min}$ ) at $800{ }^{\circ} \mathrm{C}$. 


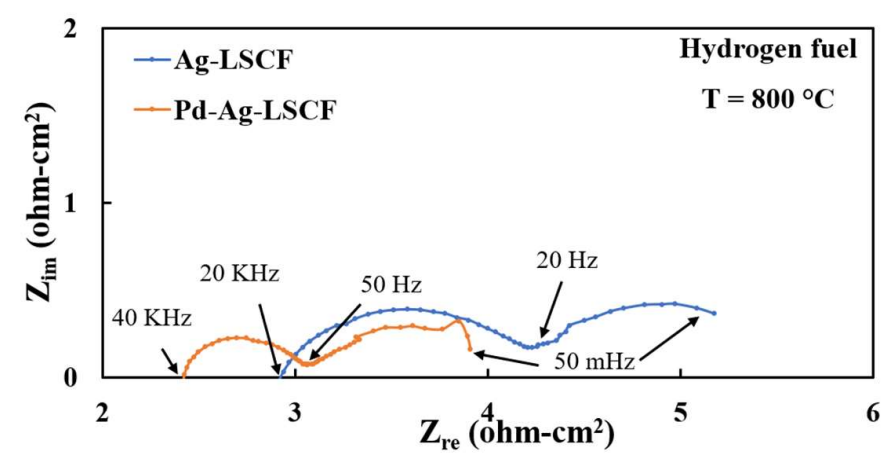

Figure 8. Electrochemical impedance spectra for Ag-LSCF//YSZ//GDC/LSCF cell and Pd$\mathrm{Ag}-\mathrm{LSCF} / / \mathrm{YSZ} / / \mathrm{GDC} / \mathrm{LSCF}$ cell with hydrogen fuel (hydrogen $=75 \mathrm{ml} / \mathrm{min}$, air $=75$ $\mathrm{ml} / \mathrm{min})$ at $800^{\circ} \mathrm{C}$.

The contribution of LSCF cathode to the EIS of the cell must be negligible as demonstrated in our previous study [19]. Thus, the two arcs in both Ag-LSCF and Pd-Ag-LSCF electrode can be attributed to anode processes including diffusion, charge transfer, gas adsorption/desorption and hydrogen splitting on the MIEC electrode surface as well as the electrolyte / electrode interface. The fitting of the EIS spectra to simple Resistor Capacitor or Resistor - Constant phase element circuits led to significant errors with and without additional diffusion elements like Warburg impedance, perhaps due to the relatively large area of the cell and inherent noise level in the data. It is acknowledged that although the spectra are divided into two discernible arcs, the shape and magnitude of the arcs could be associated with more than two electrode processes which could be engulfed into these arcs but not resolved in the current work. We used a simple Resistor - Constant phase element for each arc using the instant fit option in Zview without resolving arc any further.

The difference in ohmic resistance for both electrodes is surprising, as the addition of palladium in small amounts is unlikely to affect the ohmic resistance. It should be noted that for both cells the electrolyte disk was fabricated from the same batch. Thus, differences could be attributed to the variations in cell fabrication arising due to manual brush coating of the electrodes. Such difference in ohmic resistance $\left(0.5 \Omega-\mathrm{cm}^{2}\right)$ could be significant at higher current densities typically observed with electrode-supported cells; however, at the low current densities with the 3 YSZ electrolyte supported cells, this difference is expected to have an insignificant effect on the power density. On the other hand, the difference in polarisation resistance is more conspicuous with polarisation resistance reduced to almost half with the addition of palladium. Both low-frequency and high-frequency arcs seem to be reduced in magnitude. This can be attributed to the so-called hydrogen spill-over effect over the electrode supported Pd particles as elucidated in previous research studies [20].

\subsection{Electrode performances with ammonia fuel}

Figure 9 shows the I-V-P curve for the cell with Ag-LSCF electrode when anode gas is switched from hydrogen to ammonia. The data for hydrogen is also replotted for direct comparison. The OCV with ammonia fuel was about $1.2 \mathrm{~V}$ while for hydrogen it was $1.06 \mathrm{~V}$. The maximum power density achieved with ammonia was about $51 \mathrm{~mW} / \mathrm{cm}^{2}$ which is lower by $15 \%$ than that achieved with hydrogen fuel. The polarization curves for both fuels appear to be dominated by resistive losses, which is typical of an electrolyte-supported cell in particular with a $3 \mathrm{YSZ}$ electrolyte. I-V curves do not show any limiting current behaviour at $800{ }^{\circ} \mathrm{C}$. 


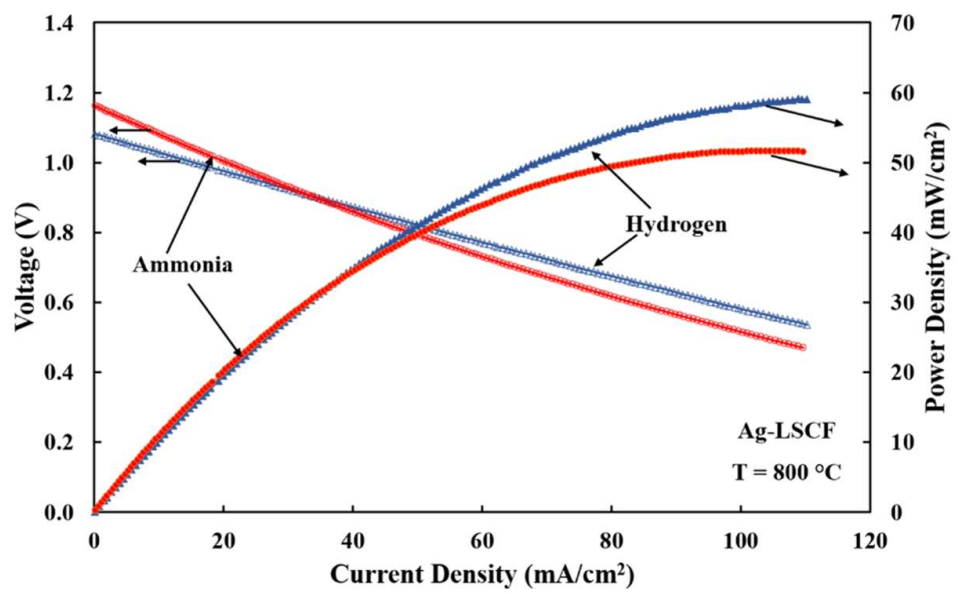

Figure 9. Voltage-current-power density characteristics of Ag-LSCF//YSZ//GDC/LSCF cell with hydrogen (hydrogen $=75 \mathrm{ml} / \mathrm{min}$, air $=75 \mathrm{ml} / \mathrm{min}$ ) and ammonia fuel (ammonia = $50 \mathrm{ml} / \mathrm{min}$, air $=75 \mathrm{ml} / \mathrm{min}$ ) at $800{ }^{\circ} \mathrm{C}$.

Figure 10 shows the EIS plots for Ag-LSCF anode with hydrogen and ammonia fuels. The polarization resistance associated with both HF and LF arcs have increased with switching the anode gas from hydrogen to ammonia. This further supports the observation that both arcs in the EIS spectra appears to be dominated by anodic processes with only a small contribution from the cathode or air electrode. However, in comparison to HF arcs, the increase in the resistance associated with LF arcs appears to be significant. LF arc increased from $1.4 \mathrm{ohms}-$ $\mathrm{cm}^{2}$ for hydrogen fuel to almost $4 \mathrm{ohms}-\mathrm{cm}^{2}$ for ammonia. The reaction mechanism is complicated, and it is difficult to ascribe the arcs precisely to particular anodic processes. Usually, the low-frequency arcs are associated with kinetically slower processes like adsorption of bigger molecules or diffusion related processes. Thus, these two factors can contribute to the observed increase in the magnitude of LF arc, however, the fact that no limiting current behaviour was observed in the I-V curve and absence of Warburg type diffusion behaviour in EIS hints to the possibility of a slower process related to adsorption of bigger molecules.

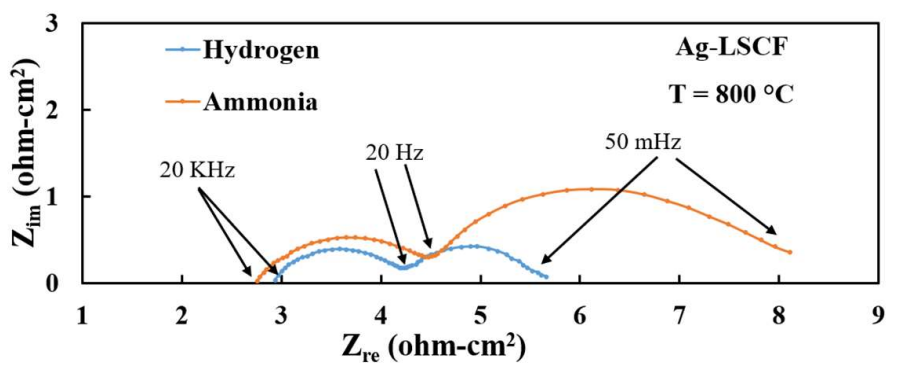

Figure 10. Electrochemical impedance spectra for Ag-LSCF//YSZ//GDC/LSCF ESC with hydrogen (hydrogen $=75 \mathrm{ml} / \mathrm{min}$, air $=75 \mathrm{ml} / \mathrm{min}$ ) and ammonia fuel (ammonia $=50$ $\mathrm{ml} / \mathrm{min}$, air $=75 \mathrm{ml} / \mathrm{min}$ ) at $800{ }^{\circ} \mathrm{C}$.

In the current experiment, the flow rate of ammonia was $50 \mathrm{ml}$ per minute which assumes complete cracking can produce $75 \mathrm{ml}$ per minute of hydrogen. Using Faradays Law, a current density of up to $1 \mathrm{~A} / \mathrm{cm}^{2}$ can be produced with this amount of hydrogen. However, the dilution 
effect of nitrogen may reduce the availability of the electrochemically active sites for hydrogen adsorption and subsequent oxidation reactions.

Considering the operating temperature in this work is well above the thermodynamic cracking temperature for ammonia $\left(430{ }^{\circ} \mathrm{C}, 1 \mathrm{~atm}\right)$ [21], the possibility of direct electrochemical oxidation of ammonia seems counterintuitive. However, it should be noted that the degree of cracking is also dependent on reactor design and residence time of ammonia inside the reactor. Analysis of exhaust gas from ammonia fed SOFC can be difficult because of the presence of the steam and more elaborate setup will be required for gas analysis. In this instance, we analysed the product gas of the system using $\mathrm{pH}$ strip indicator to test the presence of ammonia in the exhaust, and the ammonia presence in the exhaust stream was confirmed. Based upon our empirical evidence there is a large quantity of ammonia in the exit gas suggesting that ammonia decomposition is incomplete in the current system.

Thus, an observed increase in LF arc could be due to slower adsorption of ammonia on the electrode (rather than nitrogen) and lower electrochemical activity of the electrode for ammonia oxidation in comparison to facile hydrogen oxidation reaction [22]. More studies with detailed analysis of exit gas and with reference electrode over the range of temperature will be required to analyse the exact mechanism of the reactions with ammonia fuel.

In case of Pd-Ag-LSCF anode, the power densities with both fuels are similar (Figure 11). The peak power density with ammonia fuel was about $73 \mathrm{~mW} / \mathrm{cm}^{2}$ and higher by $43 \%$ in comparison with Ag-LSCF without Pd. Again, the mechanism of this enhancement is not clear, but the observation is empirical in nature. It is possible that $\mathrm{Pd}$ acts as a catalyst for ammonia cracking or it leads to a faster direct electrochemical oxidation of ammonia or the combination of both phenomena can also not be ruled out. Pd is well known for its ability to dissolve hydrogen. In this work, it is likely that Pd removes hydrogen from ammonia by the dissolution of hydrogen into the Pd particles. Once saturated with hydrogen, the atomic hydrogen emancipated from $\mathrm{Pd}$ might react directly with oxygen ions readily available on the surface of the mixed ionic electronic conductor LSCF. The higher solubility and mobility of hydrogen in Pd over Ag [23] makes more adsorbed hydrogen available for electrochemical reaction at the TPB with LSCF. The performance enhancement with Pd decorated anode catalyst can be explained by this additional supply of hydrogen from the Pd and shifting of the ammonia decomposition reaction towards right. The proposed mechanism and reaction pathway are depicted in Figure 12. The EIS for both fuels are shown in Figure 13 under OCV conditions. The EIS shows a significant difference in the polarization resistances with a magnitude of both HF and LF arcs significantly lower for hydrogen fuel. However, actual power densities with both fuels are similar. If the total resistance obtained from the EIS for hydrogen fuel is calculated using the area-specific cell resistance and used to calculate the power density at particular current, the data matches reasonably well with the data from I-V curve. Remarkably, in case of ammonia, it does not match with respective I-V data. This observation indicates that under loading conditions the polarization resistance associated with electrode processes with ammonia fuel may have reduced more significantly when compared with the case of pure hydrogen fuel. This could be due to a significant reduction in the energy barrier due to continual removal of atomic hydrogen from the saturated $\mathrm{Pd}$ catalyst by the oxidation reaction with oxygen ion happening only under loading conditions. A detailed study will be required to elucidate the mechanism and reaction pathway. Nevertheless, the findings from this work clearly show the need for more studies on ammonia SOFCs rather than assuming cracking of ammonia at the anode. This is particularly true for non-nickel electrodes like the one used in this work. Although the polarisation resistance in case of ammonia as fuel increased, the performance of the cell is similar suggesting that the direct electro-oxidation reaction of 
ammonia is also a possibility. It is also possible that the consumption of ammonia in the anode is via a combined mechanism of hydrogen and ammonia electro-oxidation. The results for both the anodes are summarised in Table 2.

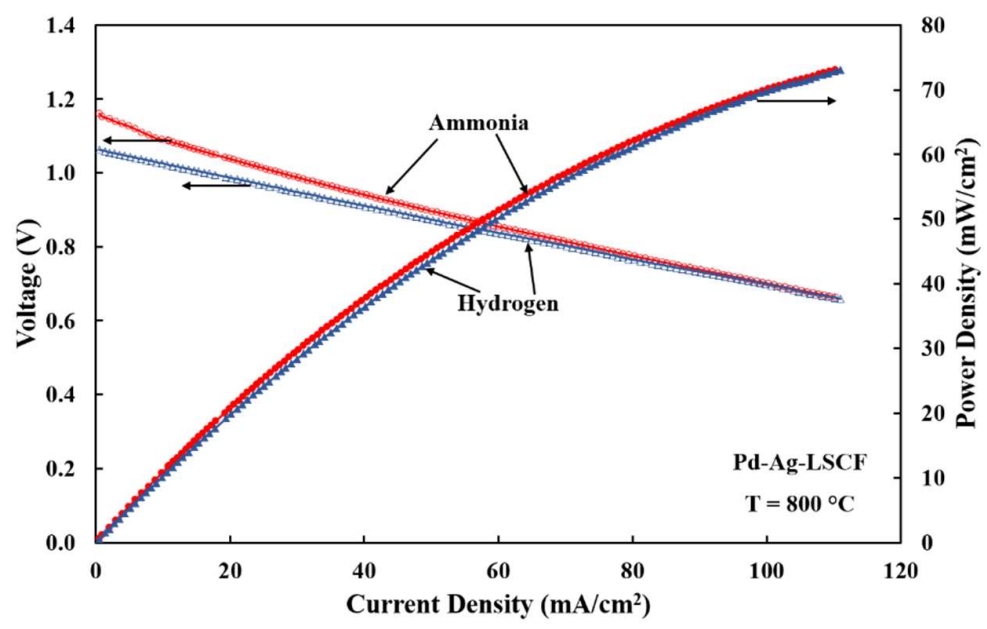

Figure 11. V-I-P for Pd-Ag-LSCF//YSZ//GDC/LSCF cell with hydrogen (hydrogen $=75$ $\mathrm{ml} / \mathrm{min}$, air $=75 \mathrm{ml} / \mathrm{min})$ and ammonia fuel $($ ammonia $=50 \mathrm{ml} / \mathrm{min}$, air $=75 \mathrm{ml} / \mathrm{min}){ }^{\circ} \mathrm{C}$.

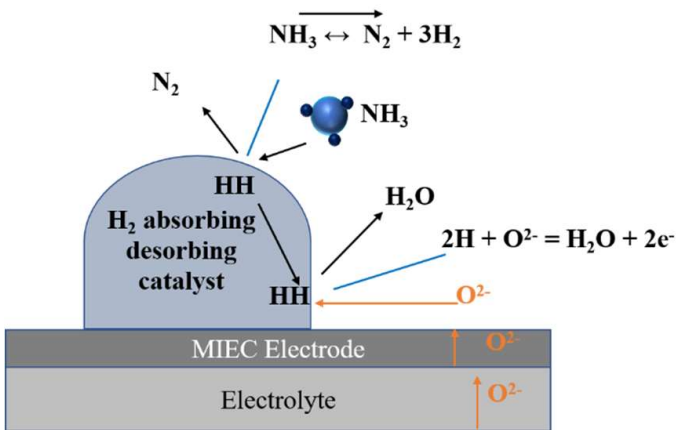

Figure 12. Schematic of proposed anode reaction mechanism showing the hydrogen absorption and shift of ammonia cracking reaction towards right.

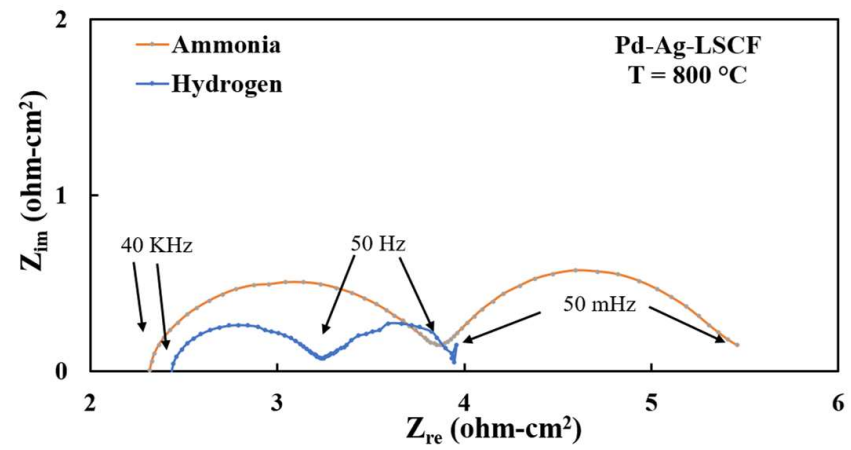

Figure 13. EIS for Pd-Ag-LSCF//YSZ//GDC/LSCF cell with hydrogen (hydrogen $=75$ $\mathrm{ml} / \mathrm{min}$, air $=75 \mathrm{ml} / \mathrm{min})$ and ammonia fuel $($ ammonia $=50 \mathrm{ml} / \mathrm{min}$, air $=75 \mathrm{ml} / \mathrm{min}$ ). 
Table 2. Results summarised for Ag-LSCF and Pd-Ag-LSCF anodes.

\begin{tabular}{|c|c|c|c|c|c|}
\hline Electrode & Fuel & $\begin{array}{c}R_{L F} \\
\left(\Omega-\mathbf{c m}^{2}\right)\end{array}$ & $\begin{array}{c}\mathbf{R}_{\mathrm{HF} \mid} \\
\left(\Omega-\mathbf{c m}^{2}\right)\end{array}$ & $\begin{array}{c}\mathbf{R}_{\mathbf{E}} \\
\left(\Omega-\mathbf{c m}^{2}\right)\end{array}$ & $\begin{array}{c}\text { Peak power density } \\
\left(\mathrm{mW} / \mathrm{cm}^{2}\right)\end{array}$ \\
\hline \multirow[t]{2}{*}{ Ag-LSCF } & Hydrogen & 5.66 & 4.25 & 2.93 & 59 \\
\hline & Ammonia & 8.11 & 4.54 & 2.76 & 51 \\
\hline \multirow[t]{2}{*}{ Pd-Ag-LSCF } & Hydrogen & 4.03 & 3.10 & 2.42 & 73 \\
\hline & Ammonia & 5.46 & 3.97 & 2.32 & 73 \\
\hline
\end{tabular}

\subsection{Short term stability testing of anode materials}

After the initial investigation of both Pd-Ag-LSCF and Ag-LSCF electrodes, the cells were subjected to short term tests with constant loading at $0.7 \mathrm{~V}$ for $65 \mathrm{hrs}$ in Chronoamperometry mode. Figure 14 and Figure 15 shows I-V curves of the cells before and after short-term tests respectively for Ag-LSCF and Pd-Ag-LSCF electrodes. With the Pd-Ag-LSCF cell the peak power density decreased from about $73 \mathrm{~mW} / \mathrm{cm}^{2}$ to $37 \mathrm{~mW} / \mathrm{cm}^{2}$ at the experiment's end. For the cell without Pd catalyst, the power density dropped from about $51 \mathrm{~mW} / \mathrm{cm}^{2}$ to $33 \mathrm{~mW} / \mathrm{cm}^{2}$. Thus, the percentage reduction for the Pd-Ag-LSCF cell was about 50\% while for Ag-LSCF it was $35 \%$. The higher degradation rate of the $\mathrm{Pd}$ impregnated anode is probably due to agglomeration of Pd particles in addition to phase changes with LSCF anode in reducing atmospheres. Figure 16 shows an SEM image of the anode after short-term testing indicating coarsening of $\mathrm{Pd}$ particles. Figure 17 shows the X-ray diffractogram after use. Table 3 compares the lattice parameter and phase assemblage for as fabricated electrodes before and after testing. It appears that LSCF electrode did not completely disintegrate into separate oxides but rather the phase assemblage changed to a mixture of tetragonal and hexagonal phases. The cell performance with the Pd decorated Ag-LSCF anode material is promising, however, issues related to coarsening needs to be addressed.

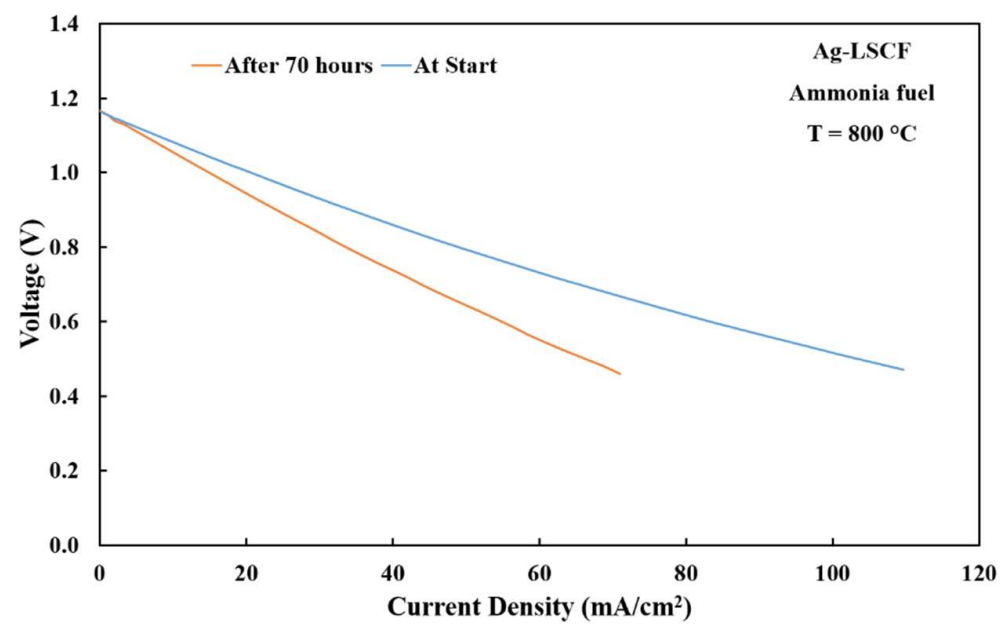

Figure 14. Voltage-current density characteristics of Ag-LSCF//YSZ//GDC/LSCF cell before and after 70 hours of operation with ammonia fuel (ammonia $=50 \mathrm{ml} / \mathrm{min}$, air $=75$ $\mathrm{ml} / \mathrm{min})$ at $800{ }^{\circ} \mathrm{C}$. 


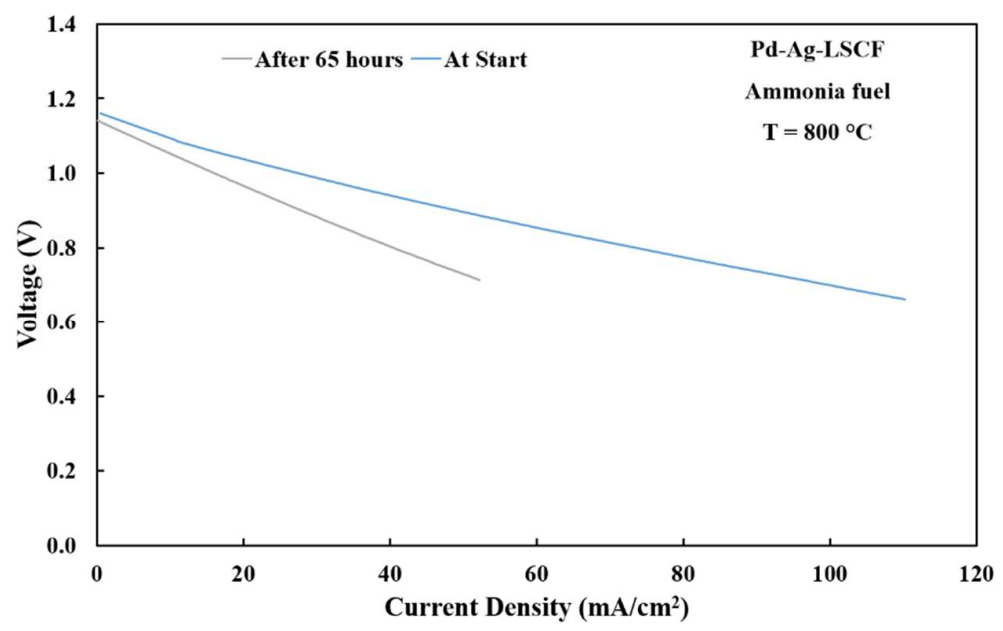

Figure 15. Voltage-current density characteristics of Pd-Ag-LSCF//YSZ//GDC/LSCF cell before and after 65 hours of operation with ammonia fuel (ammonia $=50 \mathrm{ml} / \mathrm{min}$, air $=75$ $\mathrm{ml} / \mathrm{min})$ at $800{ }^{\circ} \mathrm{C}$.

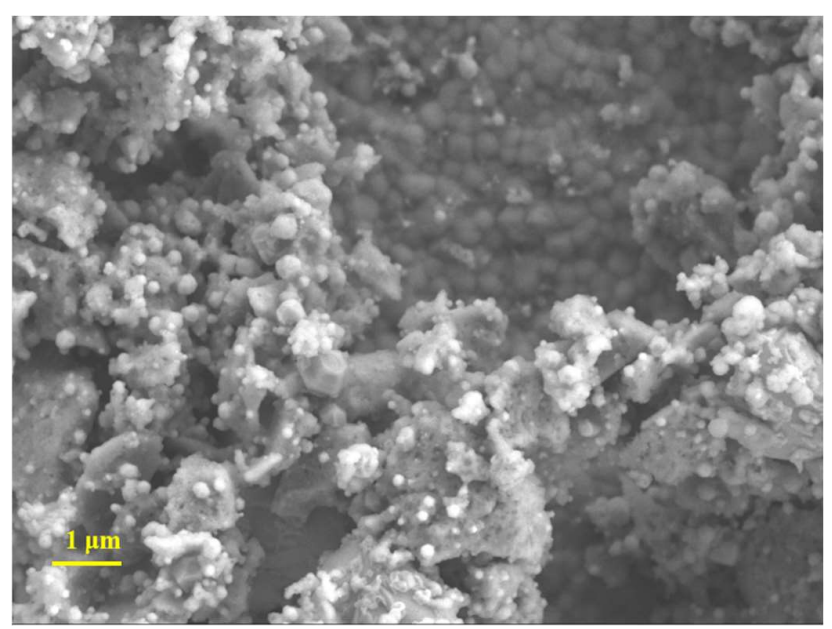

Figure 16. SEM image of Pd infiltrated Ag-LSCF anode surface after testing.

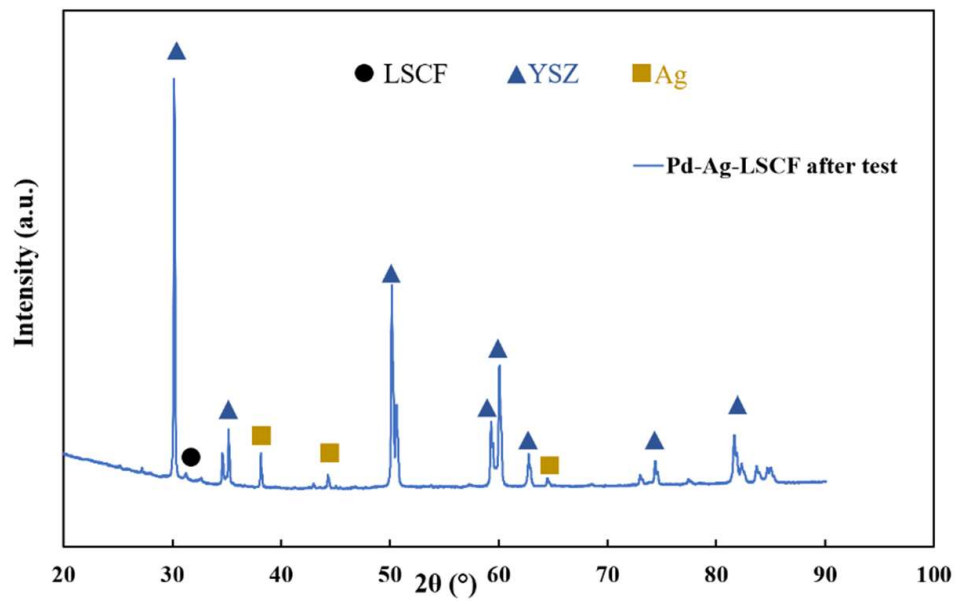

Figure 17. X-ray diffractograms collected from the Pd infiltrated Ag-LSCF anode surface after testing. 
Table 3: Phase parameters and phases found in Pd-Ag-LSCF anode before and after test.

\begin{tabular}{lcccc}
\hline Electrode & Phase & a-parameter $(\AA)$ & c-parameter $(\AA)$ & wt\% \\
\hline Pd-Ag-LSCF & Silver & - & - & $50 \pm 1$ \\
anode before test & Hexagonal LSCF & $5.48 \pm 0.001$ & $13.502 \pm 0.003$ & $50 \pm 1$ \\
\hline \multirow{2}{*}{ Pd-Ag-LSCF } & Silver & - & - & $45 \pm 6$ \\
anode after test & Hexagonal LSCF & $5.511 \pm 0.02$ & $13.65 \pm 0.08$ & $15 \pm 8$ \\
& Tetragonal LSCF & $3.875 \pm 0.002$ & $12.72 \pm 0.01$ & $40 \pm 6$ \\
\hline
\end{tabular}

\section{Conclusion}

Planar cells with the composite electrodes Ag-LSCF and Pd-Ag-LSCF were evaluated for direct ammonia fuel cell application. The electrochemical performances of the cells with these anodes were compared for hydrogen and ammonia fuels. The trends observed with opencircuit voltages hint at the possibility of direct electrochemical oxidation at lower test temperatures. The cell performance for Ag-LSCF electrode with ammonia fuel was found to be around $15 \%$ lower than that with hydrogen fuel. Addition of Pd particles to the anode led to an almost same performance with ammonia and hydrogen fuels perhaps due to hydrogen dissolution ability of $\mathrm{Pd}$ in combination with hydrogen spill-over effect. A short-term stability test indicated coarsening of Pd particles leading to a decline in the performance of the anode with additional Pd particle in combination with the phase changes associated with LSCF anode. This study indicated altercation in anodic reaction mechanism pathways in presence of hydrogen-absorbing materials like palladium for direct ammonia solid oxide fuel cells leading to enhancement in the power output of the cell. The observations in this study further confirm the need for further investigations on the electrooxidation of ammonia in SOFCs rather than assuming a complete catalytic cracking of ammonia fuel. 


\section{Supplementary Materials}

The following supplementary information is available online. Figure S1: SEM image of AgLSCF anode surface as prepared (a) and after cell operation (b).

\section{Funding}

The authors gratefully acknowledge the funding support from the CSIRO Hydrogen Future Science Platform (FSP) and CSIRO Research Office.

\section{Acknowledgments}

We are thankful to Gary Paul and Mark Greaves for providing support in the experimental work and materials characterisation, and Saheli Biswas and Gurpreet Kaur for internal review of the manuscript

\section{Author Contributions}

Shambhu Singh Rathore performed the experiments, data collection and writing of the article. Ani Kulkarni provided valuable guidance and discussions for the outline and writing of this article. Sarb Giddy also provided valuable insights for the experimental work. Daniel Fini helped in setting up the experimental equipment, performing experiments and writing of the article.

\section{Data Availability Statement}

Data is contained within the article and supplementary material

\section{Conflict of Interest}

The authors declare that they have no known competing financial interests or personal relationships that could have appeared to influence the work reported in this paper. 


\section{References}

1. Glenk, G.; Reichelstein, S. Economics of converting renewable power to hydrogen. Nature Energy 2019, 4, 216-222, doi:10.1038/s41560-019-0326-1.

2. He, T.; Pachfule, P.; Wu, H.; Xu, Q.; Chen, P. Hydrogen carriers. Nature Reviews Materials 2016, 1, 16059, doi:10.1038/natrevmats.2016.59.

3. Giddey, S.; Badwal, S.P.S.; Munnings, C.; Dolan, M. Ammonia as a Renewable Energy Transportation Media. ACS Sustainable Chemistry \& Engineering 2017, 5, 1023110239, doi:10.1021/acssuschemeng.7b02219.

4. Ma, Q.; Peng, R.; Tian, L.; Meng, G. Direct utilization of ammonia in intermediatetemperature solid oxide fuel cells. Electrochemistry Communications 2006, 8, 17911795, doi:https://doi.org/10.1016/j.elecom.2006.08.012.

5. Dekker, N.J.J.; Rietveld, G. Highly Efficient Conversion of Ammonia in Electricity by Solid Oxide Fuel Cells. Journal of Fuel Cell Science and Technology 2006, 3, 499-502, doi:10.1115/1.2349536.

6. Staniforth, J.; Ormerod, R.M. Clean destruction of waste ammonia with consummate production of electrical power within a solid oxide fuel cell system. Green Chemistry 2003, 5, 606-609, doi:10.1039/B307396N.

7. Ma, Q.; Ma, J.; Zhou, S.; Yan, R.; Gao, J.; Meng, G. A high-performance ammoniafueled SOFC based on a YSZ thin-film electrolyte. Journal of Power Sources 2007, 164, 86-89, doi:https://doi.org/10.1016/j.jpowsour.2006.09.093.

8. Liu, L.; Sun, K.; Wu, X.; Li, X.; Zhang, M.; Zhang, N.; Zhou, X. Improved performance of ammonia-fueled solid oxide fuel cell with SSZ thin film electrolyte and Ni-SSZ anode functional layer. International Journal of Hydrogen Energy 2012, 37, 1085710865, doi:https://doi.org/10.1016/j.ijhydene.2012.04.101.

9. Yang, J.; Molouk, A.F.S.; Okanishi, T.; Muroyama, H.; Matsui, T.; Eguchi, K. A Stability Study of Ni/Yttria-Stabilized Zirconia Anode for Direct Ammonia Solid Oxide Fuel Cells. ACS Applied Materials \& Interfaces 2015, 7, 28701-28707, doi:10.1021/acsami.5b11122.

10. Lan, R.; Tao, S. Ammonia as a Suitable Fuel for Fuel Cells. Frontiers in Energy Research 2014, 2, 35, doi:10.3389/fenrg.2014.00035.

11. Kulkarni, A.; Ciacchi, F.T.; Giddey, S.; Munnings, C.; Badwal, S.P.S.; Kimpton, J.A.; Fini, D. Mixed ionic electronic conducting perovskite anode for direct carbon fuel cells. International Journal of Hydrogen Energy 2012, 37, 19092-19102, doi:https://doi.org/10.1016/j.ijhydene.2012.09.141.

12. Kulkarni, A.P.; Giddey, S.; Badwal, S.P.S. Efficient conversion of $\mathrm{CO}_{2}$ in solid oxide electrolytic cells with $\mathrm{Pd}$ doped perovskite cathode on ceria nanofilm interlayer. Journal of $\mathrm{CO}_{2} \quad$ Utilization 2017, 17, 180-187, doi:https://doi.org/10.1016/j.jcou.2016.11.014.

13. Fisher, J.C.; Chuang, S.S.C. Investigating the $\mathrm{CH}_{4}$ reaction pathway on a novel LSCF anode catalyst in the SOFC. Catalysis Communications 2009, 10, 772-776, doi:https://doi.org/10.1016/j.catcom.2008.11.035.

14. Lai, B.-K.; Kerman, K.; Ramanathan, S. Nanostructured $\mathrm{La}_{0.6} \mathrm{Sr}_{0.4} \mathrm{Co}_{0.8} \mathrm{Fe}_{0.2} \mathrm{O}_{3} / \mathrm{Y}_{0.08} \mathrm{Zr}_{0.92} \mathrm{O}_{1.96} / \mathrm{La}_{0.6} \mathrm{Sr}_{0.4} \mathrm{Co}_{0.8} \mathrm{Fe}_{0.2} \mathrm{O}_{3} \quad$ (LSCF/YSZ/LSCF) symmetric thin film solid oxide fuel cells. Journal of Power Sources 2011, 196, 18261832, doi:https://doi.org/10.1016/j.jpowsour.2010.09.066.

15. Kulkarni, A.; Giddey, S.; Badwal, S.P.S. Yttria-doped ceria anode for carbon-fueled solid oxide fuel cell. J Solid State Electrochem 2015, 19, 325-335, doi:10.1007/s10008014-2604-y. 
16. Giddey, S.; Kulkarni, A.; Munnings, C.; Badwal, S.P.S. Composite anodes for improved performance of a direct carbon fuel cell. Journal of Power Sources 2015, 284, 122-129, doi:https://doi.org/10.1016/j.jpowsour.2015.02.158.

17. Kaur, G.; Kulkarni, A.P.; Giddey, S.; Badwal, S.P.S. Ceramic composite cathodes for $\mathrm{CO}_{2}$ conversion to $\mathrm{CO}$ in solid oxide electrolysis cells. Applied Energy 2018, 221, 131 138, doi:https://doi.org/10.1016/j.apenergy.2018.03.176.

18. Akimoto, W.; Saito, M.; Inaba, M.; Yoshida, H.; Inagaki, T. The Mechanism of Ammonia Oxidation at Ni-Fe-SDC Anode in Ammonia-Fueled SOFCs. ECS Transactions 2013, 57, 1639-1645, doi:10.1149/05701.1639ecst.

19. Clarke, R.E.; Kulkarni, A.; Giddey, S.; Badwal, S.P.S. Evaluation of solid electrolyte cells with a versatile electrochemical technique. Ionics 2013, 19, 265-275, doi:10.1007/s11581-012-0749-1.

20. Babaei, A.; Jiang, S.P. Analysis of fuel oxidation reaction steps in Ni/GDC anode electrode of solid oxide fuel cells by using palladium nanoparticles. In Proceedings of the Southeast Asian International Advances in Micro/Nano-technology, 2010.

21. Kalinci, Y.; Dincer, I. Analysis and performance assessment of $\mathrm{NH}_{3}$ and $\mathrm{H}_{2}$ fed SOFC with proton-conducting electrolyte. International Journal of Hydrogen Energy 2018, 43, 5795-5807, doi:https://doi.org/10.1016/j.ijhydene.2017.07.234.

22. Akimoto, W.; Fujimoto, T.; Saito, M.; Inaba, M.; Yoshida, H.; Inagaki, T. Ni-Fe/Smdoped $\mathrm{CeO}_{2}$ anode for ammonia-fueled solid oxide fuel cells. Solid State Ionics 2014, 256, 1-4, doi:https://doi.org/10.1016/j.ssi.2013.12.026.

23. Lewis, F.A. Solubility of hydrogen in metals. Pure and Applied Chemistry 1990, 62, 2091-2096, doi:doi:10.1351/pac199062112091. 